\title{
COMPOSITE FINANCIAL PERFORMANCE INDEX PREDICTION - A NEURAL NETWORKS APPROACH
}

\author{
Claudia Diana SABĂU POPA (D) ${ }^{*}$, Dorina Nicoleta POPA (D)2, \\ Victoria BOGDAN (iD ${ }^{3}$, Ramona SIMUT (D) 4 \\ 1, 2, ${ }^{3}$ Department of Finance and Accounting, Faculty of Economic Sciences, \\ University of Oradea, Oradea, Romania \\ ${ }^{4}$ Department of Economics and Business, Faculty of Economic Sciences, \\ University of Oradea, Oradea, Romania
}

Received 02 May 2020; accepted 11 November 2020

\begin{abstract}
Financial indicators are the most used variables in measuring the business performance of companies, signaling about the financial position, comprehensive income, and other significant reporting aspects. In a competitive environment, the performance measurement model allows performing comparative analysis in the same industry and between industries. This paper aims to design a composite financial index to determine the financial performance of listed companies, further used in predicting business performance through neural networks. Principal components analysis was used to build a composite financial index, employing four traditional accounting indicators and four value-based indicators for the period 2011-2018. Five experiments were conducted to predict business performance through the composite financial index. The results showed that observations from two years, of the first three experiments, indicate a better predictive behavior than the same experiments using observations from one year. Therefore, we concluded that observations from more than one year are necessary to predict the value of the financial performance index. Findings led us to the conclusion that recurrent neural networks model predicted better financial performance composite index when taken into consideration more real data for the financial performance index (2012-2018) instead of just for one year (2018).
\end{abstract}

Keywords: business performance, financial indicators, composite index, PCA, predictive behaviour, neural networks.

JEL Classification: M21, M41, L25, C45, G39.

\section{Introduction}

The financial performance is the essential component of measuring the overall performance of a company. The concern of financial analysts, investors, and managers in finding optimal models for evaluating financial performance is constantly increasing. Thus, in a highly

*Corresponding author. E-mail: dianasabaupopa@yahoo.ro

Copyright $\odot 2021$ The Author(s). Published by Vilnius Gediminas Technical University

This is an Open Access article distributed under the terms of the Creative Commons Attribution License (http://creativecommons. org/licenses/by/4.0/), which permits unrestricted use, distribution, and reproduction in any medium, provided the original author and source are credited. 
competitive business environment, the performance measurement model can make a difference within an industry. Starting from this hypothesis, the study considered that the financial performance evaluation model must consider not only traditional business financial indicators but also value-added indicators. Examining the usefulness of various financial variables in predicting, Estrella and Mishkin (1998) observed that a financial indicator can signal a problem that requires further investigation and analysis. Financial indicators are frequently used tools in predicting business failures and performance, and also are used to develop the prediction models (Huang et al., 2008). Although, many models of financial performance measurement are known, based on the grouping of indicators into profitability, solvency, liquidity, market, value-added indicators, or the use of a single indicator, considered relevant or a group formed out of two or three indicators, in this paper we chose to build a composite financial index based on panel data. Also, predicting company financial performance has been a frequent research issue in the area of business analysis and corporate reporting. Therefore, approaches based on neural networks are increasingly used in the construction of financial performance prediction models, in the last two decades.

In this paper, traditional and value-based financial indicators were used to design a neural network model for predicting the financial business performance of selected listed companies. The prediction model was built considering the composite performance index designed through principal component analysis (PCA) and a neural network approach. This paper presents briefly several previous research contributions on financial performance measurement and business prediction models. They are followed by data collection description, composite index construction methodology, business performance prediction model presentation, analysis of data, and discussion of the recurrent neural network (RNN) results. In the last section, the conclusions and limits are inserted.

\section{Business performance measurement and prediction - related works}

Through financial indicators, companies' stakeholders can understand the dynamics of their performance and found valuable information related to financial position, comprehensive income, cash flows and changes in equity and also the risks that managers face in their daily business transactions (Song et al., 2018; Elshandidy et al., 2018; Taylor et al., 2014; Li et al., 2017; Bini et al., 2015; Lehavy et al., 2011; Magnusson et al., 2005; Li, 2010). Moreover, financial performance indicators are real barometers of the success of a company. As Beaver (1966) pointed out financial ratios can make the difference between performing and failing companies. Previous studies done by Smith and Taffler (2000), Fields et al. (2001), Zhang et al. (2004), Kloptchenko et al. (2004), Qiu et al. (2014), Badulescu et al. (2020), showed that there is a wide range of ways to measure firm performance. In Kloptchenko et al. (2004), seven financial indicators were selected to characterize and measure a company's performance including, three profitability ratios, one liquidity ratio, two solvency ratios, and one efficiency ratio, while Zhang et al. (2004), used only earnings per share (EPS), to forecast financial performance. Qiu et al. (2014) used EPS, a classical accounting indicator, and size-adjusted cumulative return (SAR), a market response measure, to evaluate a company's financial strength and liquidity. Badulescu et al. (2020) 
concluded that profit, return on investment, turnover, or customer portfolio, improvements in product quality can be considered as standard indicators to measure business performance. Situm (2013) developed business failure prediction models based on multivariate linear discriminant analysis and logistic regression with the use of four selected financial indicators (equity ratio, EBIT (Earnings Before Interest and Taxes)/total assets, operating cash flow/total liabilities and percentage sales development), which led to a classification of companies in three categories (healthy, crisis-resistant and insolvency endangered). Cabinova et al. (2018) selected indicators such as EVA (Economic value-added), RONA (Return on net assets), Creditworthy Model, Simplex Linear Programming Method and examined the financial performance of the Slovakians' spa companies, during the years 2013-2017, aiming to design an Enterprise Performance Model. Song et al. (2018) chose 27 financial indicators to predict business performance with the help of traditional machine learning and the Fuzzy Chance Constrained Least Squares Twin Support Vector Machine (FCCLSTSVM) technique (Han \& Cao, 2017). The selected financial indicators reflected the companies' solvency, profitability, operational capabilities, business development capacity, structural soundness, and capital expansion capacity. Kiselakova et al. (2018) and Horváthová et al. (2015) used the Creditworthy Model (CWM), one of the modern models of enterprise performance evaluation, considered to be one of the most suitable methods for comparison business performance of enterprises. CWM has its performance portfolio, which consists of financial performance indicators and enterprise success indicators (Horváthová et al., 2015).

Predictions of business indicators, mostly forecasting corporate bankruptcy, represented a center of major interest in corporate finance and accounting research since the 1960s (Camska \& Klecka, 2020). Back then, financial prediction models described a particular economic reality (Camska \& Klecka, 2020), and were based on multivariate discriminant analysis and logistic regression (Balcaen \& Ooghe, 2006). In the last decades with the development of artificial intelligence, more and more studies have begun to use machine learning to predict financial indicators, also to predict the business performance of companies (Hu et al., 1999; Ahn et al., 2000; Huang et al., 2005; Min \& Lee, 2005; West et al., 2005; Estrella \& Mishkin, 1996; Hsu et al., 2009; Ribeiro \& Lopes, 2011; Lin et al., 2011; Li \& Sun, 2013; Shen et al., 2015). The neural network concept was firstly designed in biology and psychology, and then it was imported and used with notable results in medicine, business, and economics, and also in other research areas (Vochozka \& Sheng, 2016; Horak et al., 2020). Neural networks, a sub-domain of machine learning, based on practical data and a brief description, build algorithms that allow solving problems and making predictions. This is achieved (Bishop, 2006; Marginean et al., 2019) by learning the characteristics and testing the algorithms on the sample data to allow the introduction of static equilibrium with a new set of input data. It is worth mentioning, Vochozka and Machova (2018) observed that artificial neural networks allow the construction of strong models for various economic issues.

Björklund and Uhlin (2017) highlighted that a neural network model that predicts financial time-series requires a well-founded rational process of choosing the used parameters. Thus, several works used numerical and also narrative data, to build forecasting business performance models (Qiu et al., 2014). Quarterly reports and financial ratios were processed 
and classified using self-organizing maps, by Magnusson et al. (2005) and found that the changes in narrative reporting tend to predict changes in financial performance. Li et al. (2010) used the decision tree (DT) model for financial ratio classification and predicted the short-term business failure of Chinese listed companies. Based on back-propagation neural networks and chance-constrained least squares twin support vector machine to process uncertain data, Song et al. (2018) used financial indicators to predict business performance. They found that business performance predictions are related to the industries. Lee et al. (2017) proposed a deep neural network-based performance prediction model using financial and patent indicators.

There are some key arguments as we found in Gujarati (2002), Mulford and Comiskey (2002), and Huang et al. (2008) which support hybrid business prediction analysis, models based on machine learning techniques: the use of a large number of parameters as inputs, the selection of various financial indicators, and the choice of an efficient and accurate method to diagnose bankruptcy risk and predict company performance. Huang et al. (2008) proposed a hybrid financial analysis model based on a back-propagation neural network that showed a high prediction accuracy. The back-propagation algorithm and neural networks for financial performance prediction were also investigated by Lam (2004). The experimental results (Lam, 2004) indicated that neural networks using financial data of one year or more years exceed the minimum reference value, but not the maximum reference value. Based on six financial ratios, Elsadek et al. (2017) developed a neuro-fuzzy model to evaluate the financial performance of residential construction companies. Fuzzy clustering was performed to group the data and construct the performance index, and the neural networks model was designed to evaluate and predict the performance. Kadhim and Erzaij (2020) used principal component analysis (PCA) on road works contract projects and train artificial neural networks (ANN) model to construct criteria-performance mapping. Their results proved the nonlinear correlation between financial performance and constructors' capabilities. Maestri et al. (2019) proved that the neural networks model of financial performance forecast of the companies listed on the Brazil market obtained better accuracy than the models developed for non-listed companies.

To develop an accurate model of financial performance prediction, based on a composite indicator, this study resorted to principal component analysis (PCA). This method dates from the works of Pearson (1901) and Hotelling (1933) and has been analyzed over several decades (Cattell, 1966; Jolliffe, 2002; Jolliffe \& Cadima, 2016). The objectives of PCA are to (Abdi \& Williams, 2010) select and extract the important information from a relatively large database further, the attribute space is reduced from a larger number of variables to a smaller number of factors; select a smaller number of variables from a larger set, so that the original variables have the highest correlations with the main component.

\section{Data collection and descriptive statistics}

The study aimed to predict the financial performance of listed companies with the help of neural networks using eight financial indicators grouped into two categories, accounting, traditional indicators, and value-added indicators. They were calculated manually, for the 
years 2011-2018, using the information presented in the annual financial statements of the selected companies. The sample consists of Romanian listed companies who are required to apply International Financial Reporting Standards (IFRS), in their accounting, starting with the year 2012, according to the provisions of Order no. 881/2012. Since as of January 1, 2013, IFRSs are used as the basis of accounting for listed companies, the Ministry of Finance issued Order no. 1286/2012, which contains regulations for preparing, auditing, submission, and publication of financial statements; specific recording rules for transactions and the charter of accounts in compliance with the IFRSs, as well as the rules for transposing the accounts and presentation requirements.

The sample comprises 57 companies listed on the Bucharest Stock Exchange (BSE). For the calculation of the selected indicators, the data were collected both by accessing the company's web page and the information published on the BSE website. Thus, data was collected mainly from the statement of the financial position, profit and loss account, statement of comprehensive income, statement of cash flows, and explanatory notes, for the years 20112018. The year 2011 was chosen, for the first year of information collection and processing, as the balance of accounts drawn up on December 31, 2012, restated based on IFRSs, is the accounting document on which the individual financial statements were drawn up at the end of the financial year 2012, IFRS compliant. To ensure comparability of information from one reporting year to another, and to respect the principle of consistency and continuity of activity, we started in our study collecting information with the year 2011. The selected companies were grouped into eight industries. Thus, 39 companies were analyzed from the manufacturing industry, 4 companies from transport and storage and also, 4 companies from the wholesale and retail trade industry, 3 companies representing hotels and restaurants, 2 companies from extractive, energy and constructions industries, and a company from professional scientific and technical activities industry.

Eight financial indicators were selected to determine the financial performance of sampled companies. The indicators calculated for the present study were grouped into valueadded indicators: EVA (Economic value-added), MVA (Market value-added), CFROI (Cash flow return on investment) and CVA (Cash value-added), and classic accounting indicators: (Earnings per share), ROA (Return on assets), ROE (Return on equity) and SOL (Solvency). These indicators were calculated for each company in the sample and each year if the necessary information was disclosed and the company remained listed on the BSE. For the EVA, MVA, CFROI, and CVA indicators, those calculation formulas accepted by the accounting literature, were chosen, that allowed the determination of the indicator based on information found in the financial statements of the companies.

In Figure 1, we presented the framework of our empirical study conducted to predict financial performance through the composite index and by recourse to neural networks. The used financial indicators descriptive statistics are summarized in Table 1.

Based on the financial indicators, we aimed to build a composite performance measurement indicator, according to which the analyzed companies can be grouped into companies that performed better from one year to the next or on the contrary, and also followed the achievement of the financial performance prediction. These aspects are presented in the following sections. 


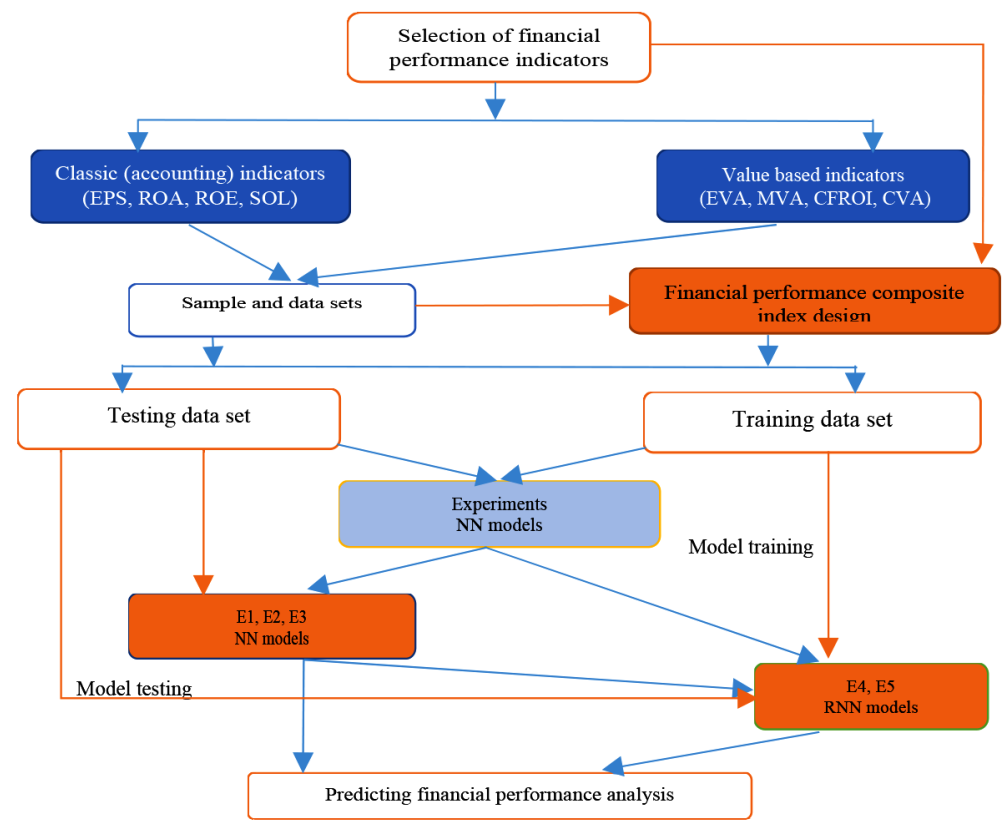

Figure 1. The framework of the empirical experiments of financial performance composite index prediction

Table 1. Descriptive statistics (source: authors' calculation)

\begin{tabular}{|l|c|c|c|c|c|c|c|c|c|}
\hline & EVA & MVA & CFROI & CVA & EPS & ROA & ROE & SOL \\
\cline { 2 - 10 } & \multicolumn{5}{|c|}{ Value-added indicators } & \multicolumn{3}{|c|}{ Classic accounting indicators } \\
\hline Mean & -9654853.8 & -806656502.8 & 0.02 & -37975205.7 & 0.31 & 0.02 & 0.08 & 5.61 \\
\hline Median & 20457.12 & -109049353.2 & 0.03 & -195155.81 & 0.04 & 0.03 & 0.06 & 3.15 \\
\hline $\begin{array}{l}\text { Mini- } \\
\text { mum }\end{array}$ & -3876998017 & -26426073015 & -1.77 & -2448487897 & -281.6 & -1.47 & -12.01 & 0.41 \\
\hline $\begin{array}{l}\text { Maxi- } \\
\text { mum }\end{array}$ & 320670806 & 2700421856 & 1.63 & 239532259.2 & 50.5 & 0.29 & 10.13 & 192.2 \\
\hline $\begin{array}{l}\text { Stan- } \\
\text { dard } \\
\begin{array}{l}\text { Devia- } \\
\text { tion }\end{array}\end{array}$ & 188641413 & 3099105272 & 0.135 & 193700972.5 & 14.6 & 0.11 & 0.82 & 11.38 \\
\hline
\end{tabular}

\section{Financial performance composite index design using PCA}

To build a performance measurement indicator, we will use PCA. This technique calculates new variables obtained as linear combinations of the original variables. These new variables are called principal components. The first principal component (PC) recovers the greatest variation from the original variables. The second PC is not correlated with the first PC and represents most of the remaining variations possible, and so on. The method will have as particularities the fact that it applies to a panel dataset. 
Given that there are significant differences between the units of measurement of the eight financial indicators analyzed, these data must be standardized. From the standardization methods presented by Freudenberg (2003) and OECD (2008), standardization transforms indicators on a common scale, with the mean 0 and the standard deviation 1. In the analysis of the principal components, different criteria are used to choose the optimal number of components. The most important criteria are Kaiser's criterion, Evrard's criterion, Benzecri's criterion (Saporta \& Stefanescu, 1996). After identifying the companies' performance factors, the next step consists in to group these determinants into a composite index. The index measures the performance of companies from one year to another using a linear scale. Because the value of the composite index can be both positive and negative, it is difficult to interpret. For a better interpretation of the results and also to realize the forecast, the index will be transformed using the rank of percentiles so that this index will take values between 0 and 100. The evaluation of the performances of the sample companies for the period 2011-2018 was based on the construction of a composite index based on panel data, identifying the determining factors in the evaluation of the performance of the analyzed companies using the analysis in principal components suitable to the panel data. The main purpose of this section is to establish the principal factors in assessing the performance of the sample companies using the Principal Component Analysis technique for panel data. This composite index will be determined using EViews 9 software (IHS Global Inc, 2017).

Table 2. Eigenvalues of the principal components (source: authors' calculation using EViews 9)

\begin{tabular}{|c|c|c|c|c|}
\hline \multicolumn{5}{|c|}{ PCA: Eigenvalues (Sample: 2011-2018) } \\
\hline Number & Value & Difference & Proportion (\%) & Cumulative proportion (\%) \\
\hline 1 & 1.893153 & 0.565034 & $23.66 \%$ & $23.66 \%$ \\
\hline 2 & 1.328119 & 0.073278 & $16.60 \%$ & $40.27 \%$ \\
\hline 3 & 1.254840 & 0.218729 & $15.69 \%$ & $55.95 \%$ \\
\hline 4 & 1.036111 & 0.088672 & $12.95 \%$ & $68.90 \%$ \\
\hline
\end{tabular}

Table 2 contains the eigenvalues for the first four principal components and the eigenvectors related to each of the principal eigenvalues. Based on Kaiser's criterion (Kaiser, 1960), only the components with the eigenvalues greater than 1 can be maintained. Thus, in our analysis, we will keep only the first four PC $\left(\lambda_{1}=1.893, \lambda_{2}=1.328, \lambda_{3}=1.254\right.$ and $\left.\lambda_{4}=1.036\right)$.

As regards the covering proportion, those four principal components preserve roughly $69 \%$ of the total variance. Therefore, if we want to reduce the dimensionality, our analysis indicates that we can reach half the basic dimensionality problem from 8 to 4 while retaining almost $70 \%$ of the original information.

The results presented in Table 3, summarizes the eigenvectors associated with each of the principal eigenvalues. If the eigenvalues show how much general information is extracted in each main component, the eigenvectors show how much weight each variable has in each component. Thus, the relative importance of any variable in a PC is the proportion of the eigenvector length assigned to that variable. 
Table 3. Eigenvectors of the principal components (source: authors' calculation using EViews 9)

\begin{tabular}{|l|c|c|c|c|c|}
\hline \multicolumn{7}{|c|}{ Principal Components Analysis (Sample: 2011-2018) } \\
\hline \multirow{2}{*}{ Variable } & PC1 & PC2 & PC3 & PC4 & PC5 \\
\cline { 2 - 6 } & \multicolumn{5}{|c|}{ PCA coefficient } \\
\hline CFROI & $-0.08(0.01)$ & $0.18(0.04)$ & $0.07(0.01)$ & $0.88(0.79)$ & $-0.20(0.04)$ \\
\hline CVA & $0.61(0.38)$ & $0.26(0.07)$ & $-0.11(0.01)$ & $0.01(0.0002)$ & $-6.09 \mathrm{E}-04(3.71 \mathrm{E}-07)$ \\
\hline EPS & $-0.29(0.09)$ & $0.45(0.21)$ & $0.42(0.18)$ & $0.13(0.02)$ & $0.18(0.03)$ \\
\hline EVA & $0.37(0.14)$ & $-0.17(0.03)$ & $0.54(0.30)$ & $-0.05(0.002)$ & $0.03(0.001)$ \\
\hline MVA & $0.56(0.31)$ & $0.41(0.17)$ & $-0.01(0.0001)$ & $0.04(0.002)$ & $0.13(0.02)$ \\
\hline ROE & $0.04(0.002)$ & $-0.31(0.10)$ & $-0.15(0.03)$ & $0.29(0.08)$ & $0.88(0.79)$ \\
\hline ROA & $-0.25(0.06)$ & $0.49(0.24)$ & $0.25(0.06)$ & $-0.31(0.10)$ & $0.34(0.12)$ \\
\hline SOL & $-0.10(0.01)$ & $0.38(0.15)$ & $-0.64(0.41)$ & $-0.04(0.001)$ & $0.04(0.001)$ \\
\hline
\end{tabular}

Note: In parenthesis - the proportion of the eigenvector length assigned to that variable.

In the case of the first eigenvector, the CVA and MVA represents $0.38 \%$, respectively $0.31 \%$ of the total component, while the other six accounts each less than $0.15 \%$ of the total component. In the second principal component, ROA and EPS represents $0.24 \%$, respectively $0.21 \%$ of the total component, SOL and EVA, represents $0.41 \%$, respectively $0.30 \%$ of the third total component, while CFROI represents $0.79 \%$ of the fourth total component and ROE, $0.79 \%$ of the fifth total component.

According to Figure 2, we can say that two variables, CVA and MVA are strongly correlated with the first main component, while the other two, ROA and EPS are strongly correlated with the second main component. In fact, by analyzing the vector lengths, we can also observe that CVA and MVA are approximately as dominant in the first component, while EPS and ROA are significantly more dominant than any of the other variables, in the second component. The angle between the vectors of a loading plot is related to the correlation

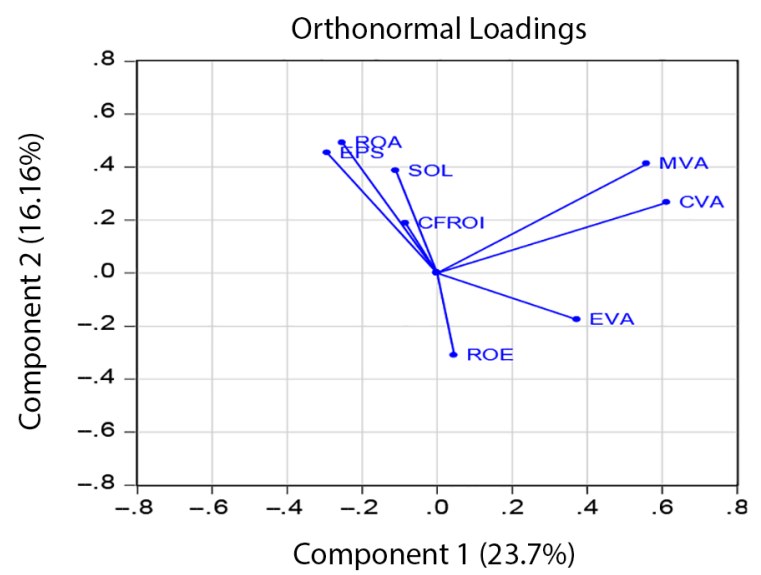

Figure 2. Orthonormal Loadings (source: authors' calculation using Eviews 9) 
between the original variables to which the loading vectors are associated. Figure 2 shows that CVA, MVA, EVA, and ROE are negatively correlated with SOL, ROA, EPS, and CFROI. Also, CVA and MVA are nearly uncorrelated with ROE since they form an angle greater than 90 degrees. Also, in the analysis of main components to facilitate the interpretation of these components, a procedure of axis rotation is used. This technique aims to obtain a correlation coefficient as low as possible on one or two main components. For numerical data, one of the most popular axis rotation techniques is the Varimax technique (Kaiser, 1958).

Table 4. Factor matrix (source: authors' calculation using EViews 9)

\begin{tabular}{|c|c|c|c|c|}
\hline \multicolumn{5}{|c|}{ Rotation Method: Orthogonal Varimax } \\
Kaiser row weighting (Convergence achieved after 7 iterations) \\
\hline Variable & Factor 1 & Factor 2 & Factor 3 & Factor 4 \\
\hline CVA & 0.759307 & -0.141593 & 0.049939 & -0.070707 \\
\hline MVA & 0.754544 & 0.043837 & 0.058102 & 0.014156 \\
\hline ROA & -0.067743 & 0.446975 & -0.080584 & 0.032063 \\
\hline EPS & -0.118219 & 0.476106 & 0.020358 & 0.225404 \\
\hline EVA & 0.220118 & 0.050974 & 0.492266 & -0.059985 \\
\hline SOL & 0.062694 & 0.051041 & -0.476778 & 0.012628 \\
\hline CFROI & -0.008721 & 0.043310 & -0.02742 & 0.284041 \\
\hline ROE & -0.026831 & -0.181419 & 0.017295 & 0.005693 \\
\hline
\end{tabular}

For the proper interpretation of the principal components, we calculated the correlation coefficients among the initial variables and the four principal components. Analyzing the matrix factor presented in Table 4, it can be seen that: the first PC is positive, correlated with CVA (0.759) and MVA (0.754) variables; the second principal component take positive information from ROA (0.446), respectively from EPS (0.476) and negative information from ROE (0.18); the third principal component is positive correlated with EVA (0.492) and negatively correlated with SOL (0.476); the fourth one is correlated with CFROI (0.284). In the last stage of the composite index construction, we determined the weights of the rotated principal component matrix, considering that each principal component has a share equal to its proportion of variance recovered from the total variation explained by all factors $(P C 1-$ 23.66\%, PC2 - 16.6\%, PC3 - 15.69\% and PC4 - 12.95\%). Thus, the financial performance index (FPI) of companies is determined as follows:

$$
F P I=\frac{23.66}{68.90} P C 1+\frac{16.60}{68.90} P C 2+\frac{15.69}{68.90} P C 3+\frac{12.95}{68.90} P C 4 .
$$

The final amount granted to each observation for each company is rescaled utilizing the percentage rank. Thus, the composite index of financial performance will indicate how a company has evolved in a year compared to the previous year or with another company in the same year or different years. The index will be between 0 (lowest performance) and 100 (highest performance). 


\section{Description of the prediction model using neural networks}

A basic model of an artificial neural network comprises three elements: input, hidden and output layers and each layer has a set of neurons, which allows the connection with the neurons of the next layer (Hu et al., 2018). A neural network model is based on the mathematical formula (Hu et al., 2018):

$$
O_{k}=u_{2}\left[\sum_{j=1}^{K} W_{j}^{k} u_{1}\left(\sum_{i=1}^{R} W_{i}^{j} x_{i}+W_{o}^{j}\right)+W_{o}^{k}\right],
$$

where: $x_{i}$ is the input, with $i=1,2, \ldots, R, O_{k}$ is the output, with $k=1,2, \ldots, K, u_{1}$ is the nonlinear activation function for the hidden layer, $\mathrm{u}_{2}$ is the linear activation function for the output layer. $R$ is the number of inputs, $K$ is the number of hidden neurons, $W_{o}^{j}$ and $W_{o}^{k}$ are thresholds of the $j$ th neuron in the hidden layer, and the $k$ th neuron in the output layer. $W_{i}^{j}$ is the weight associated with the connection between the $i$ th input and the $j$ th hidden neuron, and $W_{j}^{k}$ is the weight associated with the connection between the $j$ th hidden neuron and the $k$ th output neurons. Recurrent neural networks (RNN) are the most commonly used types of neural networks for sequence prediction issues (Hewamalage et al., 2019). Various types of RNN architectures can be found in the literature. In the present study in E4, we performed Sequence to Vector (S2V) and in E5, we used RNN Sequence to Sequence (S2S) model, inspired by Sutskever et al. (2014).

The dataset includes observations for eight years. To predict the financial performance index for a certain year, observations from previous years are used. The simplest idea would be to predict for the next year based only on what happens this year. But, if not only the values but also the evolution of the parameters influences the prediction, then the prediction should consider observations from more than the current year. Therefore, we were interested in obtaining the neural network model that can predict with the best accuracy, the evolution of the financial performance composite index. The model will consider only the variables that will have a significant influence on the composite index. The neural network with the best performance in training, testing, and cross-validation, of the data set and minimal error, but also an accurate interpretation, will be selected (Vochozka \& Machova, 2018). In this regard, we performed 5 experiments -2 classifications and 3 regressions, with feed-forward neural networks (E1, E2, E3), respectively recurrent neural networks (E4, E5). The networks were built and trained with Tensorflow2 and Python 3.6.

E1. Classify observations of one year in two classes: 1 if the index increases in the next year and 0 if the index decreases in the next year. There are 196 cases where the index decreased in the next year and 185 cases of increase (out of a total of 381). The first experiment E1 involved training a relatively small feed-forward neural network for classification in these two classes. Since there are cases where the financial performance index increased or decreased with a very small amount, we considered also a split in 3 classes: increased with more than a threshold $t\left(\Delta\right.$ index $=$ index $_{\text {year }}-$ index $\left._{\text {year }-1}>t\right)$, almost the same $-t<\Delta$ index $<t$, decreased with more than $t$. Therefore, in the experiment E2, a similar network was trained with three classes, for $t=0.0015$. With this value for $t$, there are 123 cases in class 0 - decrease, 140 in class 1 - almost the same value for the index, respectively 118 in class 2 - increase. 
Table 5. Number of samples in E1 and E2 (source: authors' calculation)

\begin{tabular}{|c|c|c|c|c|c|c|}
\hline $\begin{array}{c}\text { Increase } \\
\text { (class 1) }\end{array}$ & $\begin{array}{c}\text { Decreases } \\
\text { (class 0) }\end{array}$ & Total & $\begin{array}{c}\text { Increase } \\
\text { more than t }\end{array}$ & $\begin{array}{c}\text { Almost the } \\
\text { same }\end{array}$ & $\begin{array}{c}\text { Decrease } \\
\text { more than t }\end{array}$ & $\begin{array}{c}\text { Increase } \\
\text { (class 1) }\end{array}$ \\
\hline 185 & 196 & 381 & 118 & 140 & 123 & 185 \\
\hline 157 & 166 & 323 & 96 & 121 & 106 & 157 \\
\hline
\end{tabular}

E2. Classify observations of two successive years in two classes (increase/decrease), respectively 3 classes as in E1.

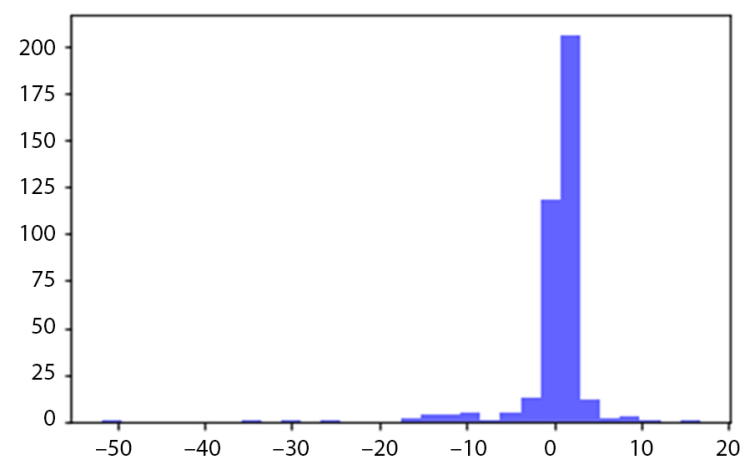

Figure 3. Histograms of values for FP index in years 2012-2018 (without 2011)

E3. Perform a regression for the financial performance index value, meaning predict the value for the next year based on observations for the current year. Since the values are very small, we predict the index ${ }^{\star} 100$. Consequently, the range is $(-51.83,16.72)$.

Table 6. NN structure for E1 and E2/Regression NN for 2 years E1, E2 (source: authors' calculation)

\begin{tabular}{|c|c|c|c|c|c|}
\hline \multicolumn{3}{|c|}{ Neural networks structure for E1 and E2 } & \multicolumn{3}{|c|}{ Regression neural networks for 2 years E1, E2 } \\
\hline Layer (type) & Output Shape & Param \# & Layer (type) & Output Shape & Param \# \\
\hline dense_37 & (None, 32) & 688 & dense_25 & (None, 32) & 688 \\
\hline dropout_19 & (None, 32) & 0 & dropout_12 & (None, 32) & 0 \\
\hline dense_38 & (None, 8) & 264 & dense_26 & (None, 16) & 528 \\
\hline dropout_20 & (None, 8) & 0 & dropout_27 & (None, 1) & 17 \\
\hline dense_39 & (None, 3) & 27 & \multirow{2}{*}{\multicolumn{3}{|c|}{$\begin{array}{l}\text { Total params: 1153/Trainable params: } 1153 / \\
\text { Non-trainable params: } 0\end{array}$}} \\
\hline $\begin{array}{l}\text { Total params: } \\
\text { Non-trainable }\end{array}$ & $\begin{array}{l}\text { 9/Trainable par } \\
\text { arams: } 0\end{array}$ & & & & \\
\hline
\end{tabular}

The network trained in E1 and E2 has 5 layers (Table 6): a Dense with 32 neurons, a Dropout with probability $=0.4$, another Dense with eight neurons together with another Dropout, and lastly a softmax layer. As it can be observed in Table 5, the number of samples is very small, which affects the quality of the trained network. E4 and E5 perform recurrent neural networks as described in section six of the current study. 


\section{Data analysis and discussion of results}

To alleviate this, we repeated E1 and E2 on the different splitting of the datasets (similar to cross-validation) and several times on the same split in train and test. On average, E1 reaches at most accuracy 0.63 on train and 0.61 on the test set, while in E2 the values are smaller.
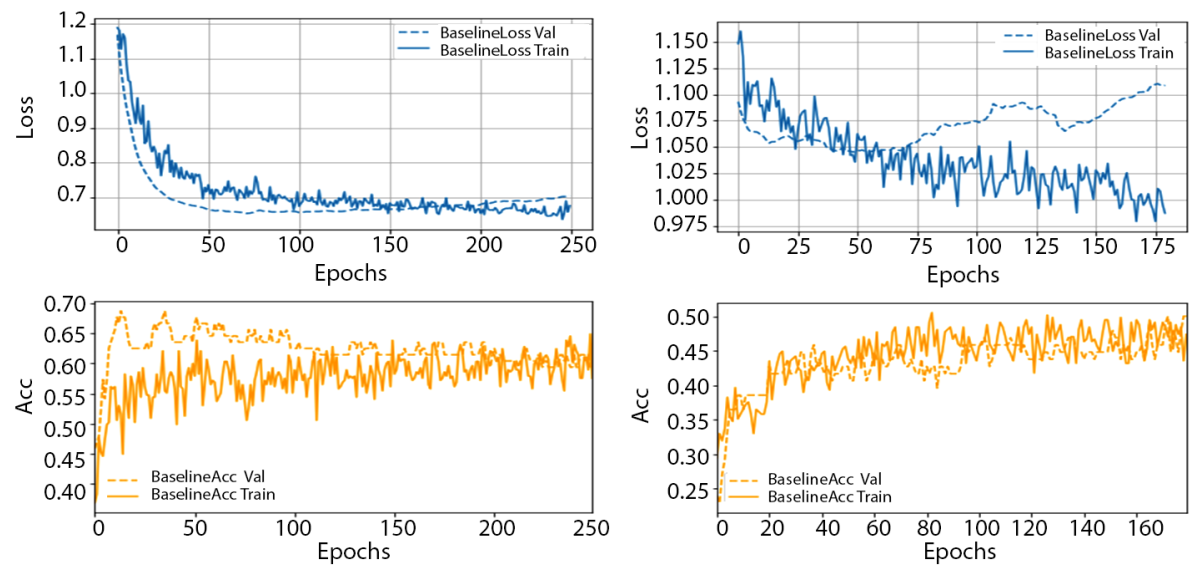

Figure 4. Classification: Left - exp E1a), right - exp E2a), classification in classes with observations from one year

In Figure 4 it can be observed that overfitting appears in E1 around epoch 180 when the loss on validation starts to increase, while on train set it continues to decrease. The addition of the third class in E2 does not improve the accuracy, on average the values of accuracy are below 0.5; a possible reason is a wrong value for the threshold. The current value for threshold was set such that the resulting dataset is balanced (similar number of samples in all three classes). As it can be observed from the histogram in Figure 3, the majority of values for $100 \times$ index are around 0 , with a small number of values at the margins of the interval.

As expected, the model trained in E3 reaches MSE (mean squared error) significantly worse than MAE (mean absolute error) (see Figure 3). Consequently, for the experiments with RNN, we tried to change the distribution of values, so instead of $10{ }^{*}$ index, we used $\operatorname{sign}($ index $) \times \sqrt{\text { index } \vee}$ which shrinks the values greater than 1 and increases the values between $(-1,1)$.

Further on, all three experiments (E1, E2, E3b)) were repeated with the same output but with observations from two years instead of just one year as an input. For regression (E3), the values of MAE and MSE for train and test set improved significantly (see Figure 5 - for metrics values, we mention first the value obtained on the train followed by the one obtained on test; the values are the average of the best-obtained values in 10 repeated experiments).

In Figure 6, it can be observed that MAE improved from an average of $0.87 / 1.37$ to an average of $0.27 / 0.18$. More important, MSE improved from $2.71 / 12$ to $0.34 / 0.41$. The improvement of both metrics on both train and test sets can support the conclusion that the value for the financial performance index in the next year depends not only on the values for the 

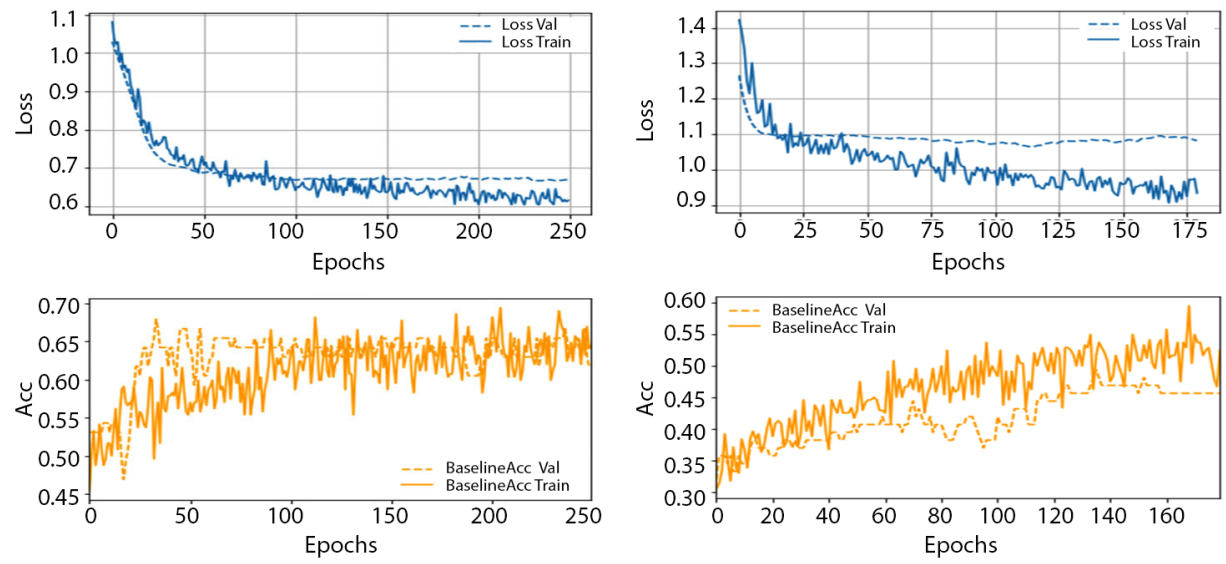

Figure 5. E2b) and E3b), classification in two, respectively 3 classes with observations from 2 years
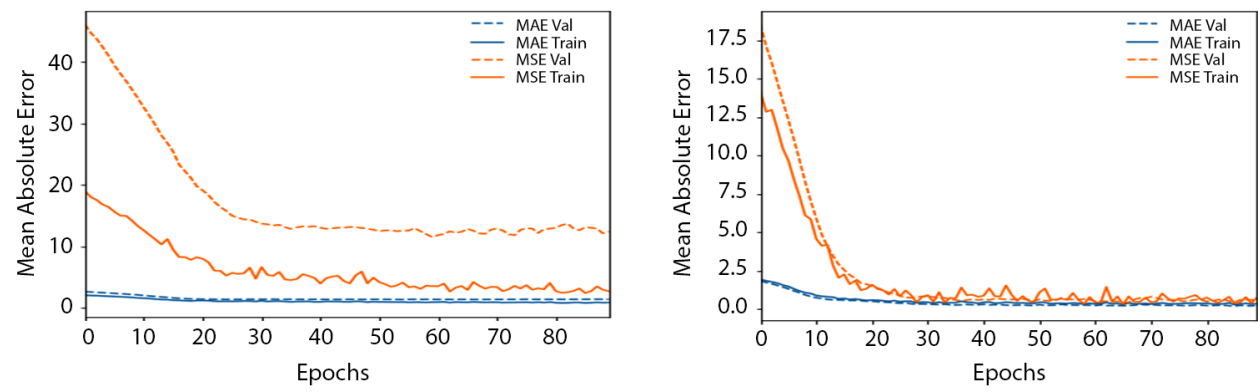

Figure 6. Experiment E3. Regression with observations from one year (average MAE $=0.87 / 1.37, \mathrm{MSE}=2.71 / 12)$ E3a) left; observations from two years $($ average $\mathrm{MAE}=0.27 / 0.18, \mathrm{MSE}=0.34 / 0.41)-\mathrm{E} 3 \mathrm{~b})$ right

current year but also on the values of the previous year. The fact that for E3 a), in the majority of the experiments, the values for MSE on validation are much higher than the values on the train set must be correlated with the meaning of MSE (i.e. the average of the squares of the errors) and with the histogram of the index: the trained models do large errors (especially on new data) which are emphasized through squaring. This behavior which is a sign of a bad prediction model is not present anymore on E3b), meaning that the observations from more than one year are necessary to predict the value of the performance index. When it comes to classification, E1 and E2 did not change significantly when two years were considered, the only stable difference is that in E1, the overfitting - identified as a greater loss on test set compared to test set - appears sooner at almost the same value of loss and accuracy (around epochs 100 in E1b compared to epochs 180 in E1a)), meaning that the model learns sooner when it gets observations from two years. The learning of three classes is still worse than learning of two classes (E2b compared to E2a). From version b) of the experiments E1, $\mathrm{E} 2$, and E3 we could conclude that the financial performance index is clearly related to the evolution of the other financial indicators and not only values from one year, therefore we continue with experiments better suited for training on sequences. 


\section{Recurrent neural networks}

Since version b) of E1, E2, and E3 proved more stable than learning from just one year, in experiments $\mathbf{E} 4$ and $\mathbf{E} 5$ we trained recurrent networks to forecast a multivariate time series. In E4 the model sequence2vector was used, while sequence2sequence in E5, and both for regression. The structure of the networks can be observed in Table 7.

Table 7. The structure of the networks in E4 and E5 (source: authors' calculation)

\begin{tabular}{|l|l|c|l|l|c|}
\hline \multicolumn{3}{|c|}{ RNN structure for E4 and E5 } & \multicolumn{3}{c|}{ Regression RNN E4, E5 } \\
\hline \multicolumn{1}{|c|}{ Layer (type) } & Output Shape & Param \# & Layer (type) & Output Shape & Param \# \\
\hline lstm_2 & (None, 7, 24) & 3264 & simple_rnn & (None, 7, 24) & 816 \\
\hline dropout_23 & (None, 7, 24) & 0 & dropout_9 & (None, 7, 24) & 0 \\
\hline lstm_3 & (None, 7, 12) & 1776 & simple_rnn_1 & (None, 12) & 444 \\
\hline dropout_24 & (None, 7, 12) & 0 & dense_21 & (None, 1) & 13 \\
\hline time_distributed_1 & (None, 7, 1) & 13 & Total params: 1273/Trainable params: 1273/ \\
Total params: 5053/Trainable params: 5053/ \\
Non-trainable params: 0
\end{tabular}

In the data set, we kept only companies with all indicators known for all years, meaning 48-time sequences of $8+1$ features. The loss function is MSE. First, in E4 a) we considered MSE applied only for the prediction of the index for the last year 2018. So, the network learns to predict the index for 2018 and it computes error based only on this prediction. Since it is a recurrent network, the input for a one-time step consists of the features for one year and the output of the network is passed for prediction of the next time step. In the sequence2vector approach, only the last output is used for computing the error, while in sequence2sequence all the outputs are considered, meaning that the errors consider all the predictions for the index from 2012 to 2018.

It can be observed that the best values for MAE and MSE on the train are comparable in E4 (see, Figure 7) and E5 (see, Figure 8). But in E5 the differences between MSE and

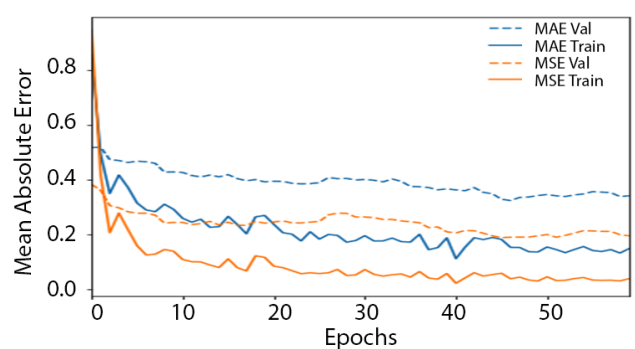

Figure 7. E4. Simple RNN for sequences of length 7 (average MSE 0.03/0.21, MAE 0.13/0.33) with the error considering the predictions for the index in 2018

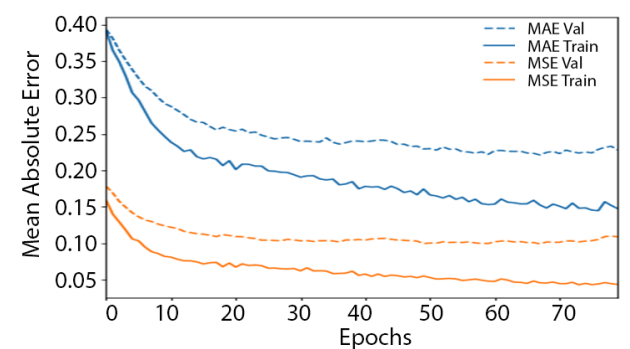

Figure 8. E5. LSTM (Long Short-Term Memory) for sequence of length 7 with error considering all predictions for the index during 2012-2018 (average MSE 0.04/0.09, MAE 0.15/0.19) 
MAE on train and test set are smaller, meaning that the models can predict better new data in E5.

This is explained by the fact that the model learns by reducing an error which considers more real data for index (2012-2018) instead of just 2018 in E4. Below, (see, Figure 9) we present some examples of financial performance index predictions given by models in E5 and $\mathrm{E} 4$ on data that were not included in the training set.

As we can see from Figure 9, the prediction model from E5, based on sequence 2 sequence and regression, considering all predictions for the composite index during 20122018, presents the best prediction.
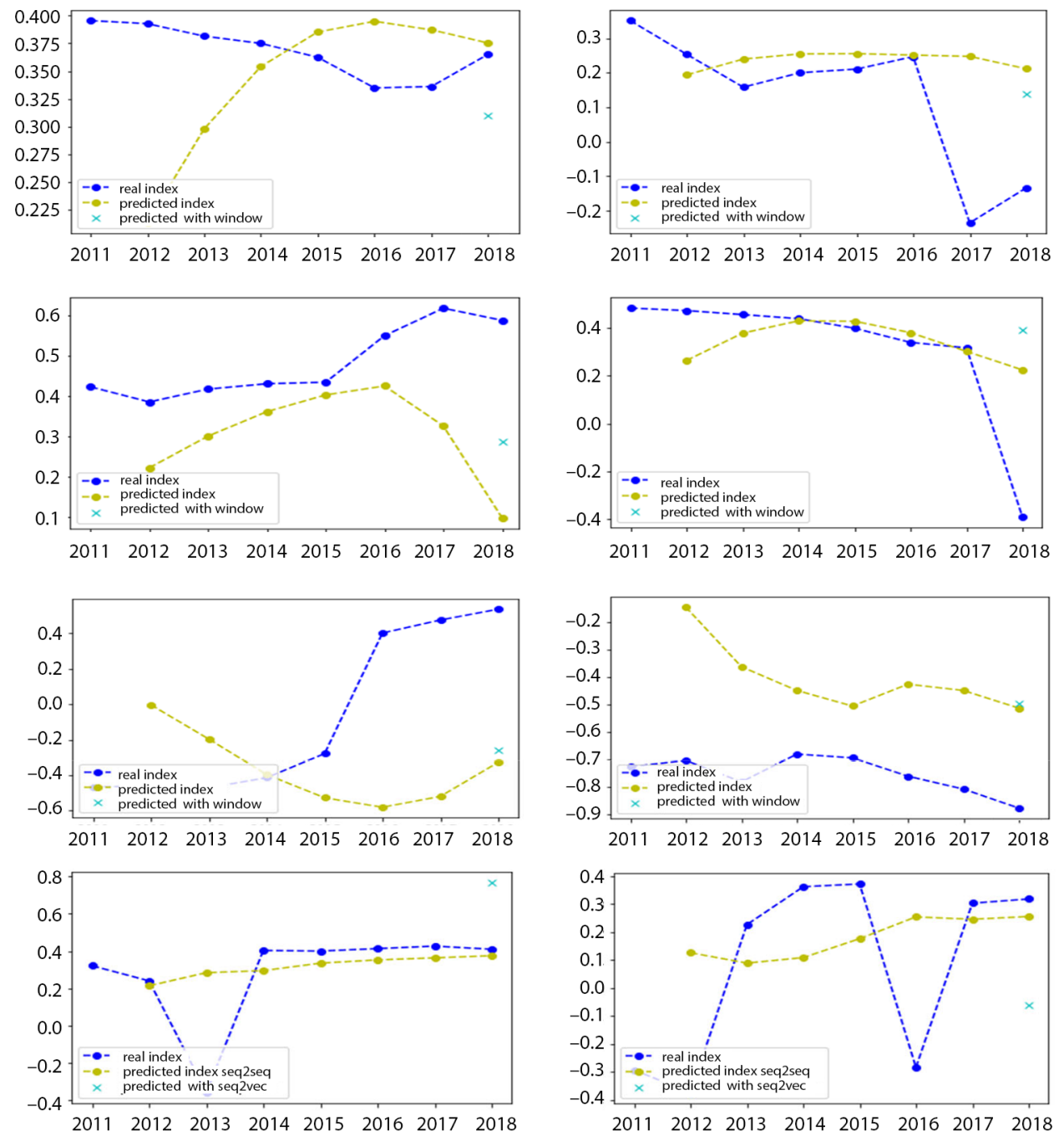

Figure 9. Examples of financial performance index predictions (models E5 and E4) on data not included in the training set 


\section{Conclusions}

This study presented a neural network financial performance prediction model for Romanian listed companies. Business performance prediction is based on a composite financial index. In this regard, starting from eight financial indicators grouped into two categories, traditional accounting indicators, and value-based indicators, a performance index was built, based on panel data. The research work was conducted in two steps, using 456 financial data about 57 Romanian listed companies. In the first step, using PCA data was classified, followed by the design of the performance index, and in the second step with the use of neural networks, a performance prediction model was developed based on the composite index and the selected financial indicators. The composite index was built to aggregate financial information on the company's performance and to facilitate the prediction of its evolution using neural networks. A composite indicator can provide a more real and relevant image of financial performance, being composed of both components of classical indicators and value-added indicators. Thus, the developed model offered a good prediction and satisfying results and can be used to evaluate and predict the financial performance of listed companies. The study contributes to the development of the literature by modeling prediction of financial performance based on the composite index, not just on the prediction of certain individual indicators.

To achieve the prediction model using neural networks, the procedure was as follows: firstly, to predict the financial performance index for a certain year, observations from previous years were used, and secondly, the study presents 3 experiments. It can be observed that version b), with observations from two years, of the experiments E1, E2, and E3 show a better predictive behavior than version a), with observations from one year, of the same experiments. So far, we have concluded that the observations from more than one year are necessary to predict the value of the financial performance index. Thus, it can be highlighted that the performance index prediction as a composite indicator is related to the evolution of the financial indicators and not only their values from one year but previous years, also. Therefore, the study continued with experiments that are more suitable for training on sequences. In experiments, E4 and E5 recurrent networks were trained. In E4 the model sequence 2 vector was used, while sequence 2 sequence in E5, and both for regression. In E5 the differences between MSE and MAE on train and test set are smaller. So, the models can predict better new data in E5. Findings from the performed experiments led us to the conclusion that recurrent neural networks model predicted better financial performance composite index when taken into consideration more real data for the index (2012-2018) instead of just 2018. Therefore, neural network models designed for the prediction of business performance can be considered useful tools for managers. Through these management tools, it is possible to build future strategies of performance optimization based on the experiences of previous years and analyzed through the lens of the current financial situation.

The limits of the financial performance prediction model can be found in a small sample of companies and the data collected from 2011 to 2018. Future research will focus on designing other business performance prediction models and with higher accuracy of the prediction, based on input data that includes not only financial variables but non-financial information, also. 


\section{Acknowledgements}

The content of this material does not necessarily represent the official position of the European Union.

\section{Funding}

This research was funded within the project Institutional cooperation in research activities for specialists, training and usage of computational intelligence for fundamenting companies' financial decisions, eMS Code: ROHU-217. The project Institutional cooperation in research activities for specialists, training and usage of computational intelligence for fundamenting companies' financial decisions is implemented under the, Interreg V-A Romania-Hungary Programme and is financed by the European Union through the European Regional Development Fund, Romania and Hungary. Partnership for a better future: www.interreg-rohu.eu.

\section{Author contributions}

VB, DNP and RS conceived the study, DNP collected the data, VB and RS designed the research methodology and developed the first analysis of the data. DSP, VB and RS were responsible for data interpretation and discussion of results. VB and RS conceived the conclusions and wrote the first draft of the study. DSP and DNP wrote the second draft of the article. All authors have read and agreed to the published version of the manuscript.

\section{Disclosure statement}

Authors do not have any competing financial, professional, or personal interests from other parties.

\section{References}

Abdi, H., \& Williams L. J. (2010). Principal component analysis. WIREs Computational Statistics, 2(4), 433-459. https://doi.org/10.1002/wics.101

Ahn, B. S., Cho, S. S., \& Kim, C. Y. (2000). The integrated methodology of rough set theory and artificial neural network for business failure prediction. Expert Systems with Applications, 18(2), 65-74. https://doi.org/10.1016/S0957-4174(99)00053-6

Badulescu, A., Badulescu, D., \& Stiubea, E. (2020). How do new ventures operating in tourism industry relate to their financial goals? In V. Katsoni \& T. Spyriadis (Eds.), Cultural and tourism innovation in the digital era (pp. 521-531). Springer. https://doi.org/10.1007/978-3-030-36342-0_40

Balcaen, S., \& Ooghe, H. (2006). 35 years of studies on business failure: An overview of the classic statistical methodologies and their related problems. The British Accounting Review, 38, 63-93. https://doi.org/10.1016/j.bar.2005.09.001

Beaver, W. H. (1966). Financial ratios as predictors of failure. Empirical Research in Accounting: Selected Studies 1966, 4, 71-111. https://doi.org/10.2307/2490171

Bini, L., Dainelli, F., \& Giunta, F. (2015). Is a loosely specified regulatory intervention effective in disciplining management commentary? The case of performance indicator disclosure. Journal of Management \& Governance, 21(1), 63-91. https://doi.org/10.1007/s10997-015-9334-0 
Bishop, C. M. (2006). Pattern recognition and machine learning. Springer.

Björklund, S., \& Uhlin, T. (2017). Artificial neural networks for financial time series prediction and portfolio optimization (Advisor Jörgen Blomvall). Linköping University.

Cabinova, V., Onuferova E., Gallo, P. Jr., Gallo, P., \& Gallo, J. (2018). A comparative analysis of modern performance methods in economic practice. Montenegrin Journal of Economics, 14(4), 085-096. https://doi.org/10.14254/1800-5845/2018.14-4.6

Camska, D., \& Klecka, J. (2020). Comparison of prediction models applied in economic recession and expansion. Journal of Risk and Financial Management, 13(52), 1-16. https://doi.org/10.3390/jrfm13030052

Cattell, R. B. (1966). The scree plot test for the number of factors. Multivariate Behavioral Research, 1(2), 245-276.

Elsadek, M., Elshakour, H. A., \& Elyamany, A. (2017). Developing a neural networks model for evaluating financial performance of residential companies based on FCM. Journal of Mechanical and Civil Engineering (IOSR - JMCE), 44(2), 46-59. https://doi.org/10.9790/1684-1402024659

Elshandidy, T., Neri, L., \& Guo, Y. (2018). Determinants and impacts of risk disclosure quality: Evidence from China. Journal of Applied Accounting Research, 19(4), 518-536. https://doi.org/10.1108/JAAR-07-2016-0066

Estrella, A., \& Mishkin, F. S. (1998). Predicting US recessions: Financial variables as leading indicators. Review of Economics and Statistics, 80(1), 45-61. https://doi.org/10.1162/003465398557320

Fields, T. D., Lys, T. Z., \& Vincent, L. (2001). Empirical research on accounting choice. Journal of Accounting and Economics, 31(1-3), 255-307. https://doi.org/10.1016/S0165-4101(01)00028-3

Freudenberg, M. (2003). Composite indicators of country performance: A critical assessment (OECD Science, Technology and Industry Working Papers, 2003/16). OECD Publishing.

Gujarati, D. N. (2002). Basic econometrics (4th $\mathrm{ed}$.). McGraw-Hill Higher Education.

Han, R. J., \& Cao, Q. L. (2017). Fuzzy chance-constrained least squares twin support vector machine for uncertain classification. Journal of Intelligent \& Fuzzy Systems, 33(5), 3041-3049. https://doi.org/10.3233/JIFS-169355

Hewamalage, H., Bergmeir, C., \& Bandara, K. (2019). Recurrent neural networks for time series forecasting: Current status and future directions. International Journal of Forecasting, 37(1), 388-427. https://doi.org/10.1016/j.ijforecast.2020.06.008

Horak, J., Vrbka, J., \& Suler, P. (2020). Support vector machine methods and artificial neural networks used for the development of bankruptcy prediction models and their comparison. Journal of Risk and Financial Management, 13(3), 1-15. https://doi.org/10.3390/jrfm13030060

Horváthová, J., Mokrišová, M., Suhányiová, A., \& Suhányi, L. (2015). Selection of key performance indicators of chosen industry and their application in the formation of creditworthy model. Proceedia Economics and Finance, 34, 360-367. https://doi.org/10.1016/S2212-5671(15)01641-X

Hotelling, H. (1933). Analysis of a complex of statistical variables into principal components. Journal of Educational Psychology, 24(7), 498-520. https://doi.org/10.1037/h0070888

Hsu, S., Hsieh, J., Chih, T., \& Hsu, K. (2009). A two-stage architecture for stock price forecasting by integrating the self-organizing map and support vector regression. Expert Systems with Applications, 36(4), 7947-7951. https://doi.org/10.1016/j.eswa.2008.10.065

Hu, C., Wu, Q., Li, H., Jian, S., Li, N., \& Lou, Z. (2018). Deep learning with a long short-term memory networks approach for rainfall-runoff simulation. Water, 10(11), 1543, 1-16. https://doi.org/10.3390/w10111543

Hu, M. Y., Jiang, C. X., \& Patuwo, E. (1999). A cross-validation analysis of neural network out-ofsample performance in exchange rate forecasting. Decision Sciences, 30(1), 197-216. https://doi.org/10.1111/j.1540-5915.1999.tb01606.x 
Huang, S. M., Tsai, C. F, Yen, D. C., \& Cheng, Y. L. (2008). A hybrid financial analysis model for business failure prediction. Expert Systems with Applications, 35(3), 1034-1040. https://doi.org/10.1016/j.eswa.2007.08.040

Huang, W., Nakamori, Y., \& Wang, S. (2005). Forecasting stock market movement direction with support vector machine. Computers \& Operations Research, 32(10), 2513-2522. https://doi.org/10.1016/j.cor.2004.03.016

IHS Global Inc. (2017). EViews 9. Student/Lite Version [Computer software for windows]. http://www.eviews.com/download/student9/EViews\%209\%20Student\%20Version.pdf

Jolliffe, I. T. (2002). Principal component analysis ( $2^{\text {nd }}$ ed.). Springer-Verlag Press.

Jolliffe, I. T., \& Cadima, J. (2016). Principal component analysis: A review and recent developments. Philosophical Transactions of the Royal Society A: Mathematical, Physical and Engineering Sciences, 374(2065), 20150202. https://doi.org/10.1098/rsta.2015.0202

Kadhim, S. N., \& Erzaij, K. R. (2020). A neural network model for financial performance prediction: The case for road works in Bahrain. Test Engineering \& Management, 82, 1589-1599.

Kaiser, H. F. (1958). The varimax criterion for analytic rotation in factor analysis. Psychometrika, 23, 187-200. https://doi.org/10.1007/BF02289233

Kaiser, H. F. (1960). The application of electronic computers to factor analysis. Educational and Psychological Measurement, 20(1), 141-151. https://doi.org/10.1177/001316446002000116

Kiselakova, D., Šofranková, B., Čabinová, V., \& Šoltésová, J. (2018). Analysis of enterprise performance and competitiveness to streamline managerial decisions. Polish Journal of Management Studies, 17(2), 101-111. https://doi.org/10.17512/pjms.2018.17.2.09

Kloptchenko, A., Eklund, T., Back, B., Karlsson, J., Vanharanta, H., \& Visa, A. (2004). Combining data and text mining techniques for analyzing financial reports. Intelligent Systems in Accounting, Finance, and Management, 12(1), 29-41. https://doi.org/10.1002/isaf.239

Lam, M. (2004). Neural network techniques for financial performance prediction: Integrating fundamental and technical analysis. Decision Support Systems, 37(4), 567-581. https://doi.org/10.1016/S0167-9236(03)00088-5

Lee, J., Jang, D. S., \& Park, S. (2017). Deep learning-based corporate performance prediction model considering technical capability. Sustainability, 9(6), 899. https://doi.org/10.3390/su9060899

Lehavy, R., Li, F., \& Merkley, K. (2011). The effect of annual report readability on analyst following and the properties of their earnings forecasts. The Accounting Review, 86(3), 1087-1115. https://doi.org/10.2308/accr.00000043

Li, F. (2010). The information content of forward-looking statements in corporate filings - A Naïve Bayesian machine learning approach. Journal of Accounting Research, 48(5), 1049-1102. https://doi.org/10.1111/j.1475-679X.2010.00382.x

Li, F. Y., Jiang, Q. J., \& Ke, F. (2017, September). Discussion on financial fraud of agricultural listed companies. In The $2^{\text {nd }}$ International Conference on Humanities Science, Management and Education Technology (HSMET) (pp. 296-299). Zhuhai, China. https://doi.org/10.12783/dtssehs/hsmet2017/16503

Li, H., \& Sun, J. (2013). Predicting business failure using an RSF-based case-based reasoning ensemble forecasting method. Journal of Forecasting, 32(2), 180-192. https://doi.org/10.1002/for.1265

Li, H., Sun, J., \& Wu, J. (2010). Predicting business failure using classification and regression tree: An empirical comparison with popular classical statistical methods and top classification mining methods. Expert Systems with Application, 37(8), 5895-5904. https://doi.org/10.1016/j.eswa.2010.02.016

Lin, F., Liang, D., \& Chen, E. (2011). Financial ratio selection for business crisis prediction. Expert Systems with Applications, 38(12), 15094-15102. https://doi.org/10.1016/j.eswa.2011.05.035

Maestri, C. O. N. M., Tavares, V. B., Penedo, A. S. T., Pereira, V. S., \& Coelho, R. R. A. (2019). Does the level of corporate governance predict the financial performance of the company? Evidence from the Brazilian market through artificial neural networks. Revista Containese da Ciencia Contabil, 18, 1-14. https://doi.org/10.16930/2237-766220192796 
Magnusson, C., Arppe, A., Eklund, T., Barbro, B., Vanharanta, H., \& Visa, A. (2005). The language of quarterly reports as an indicator of change in the company's financial status. Information \& Management, 42(4), 561-574. https://doi.org/10.1016/j.im.2004.02.008

Marginean, A., Groza, A., Nicoara, S. D., Muntean, G., Slavescu, R., \& Letia, I. A. (2019, September 5-7). Towards balancing the complexity of convolutional neural network with the role of optical coherence tomography in retinal conditions. In 2019 IEEE $15^{\text {th }}$ International Conference on Intelligent Computer Communication and Processing (ICCP) (pp. 475-482). Cluj Napoca, Romania. https://doi.org/10.1109/ICCP48234.2019.8959714

Min, J. H., \& Lee, Y. C. (2005). Bankruptcy prediction using support vector machine with optimal choice of kernel function parameters. Expert Systems with Applications, 28(4), 603-614. https://doi.org/10.1016/j.eswa.2004.12.008

Mulford, C. W., \& Comiskey, E. E. (2002). The financial numbers game, detecting creative accounting practices. John Wiley \& Sons Inc.

OECD. (2008). Handbook on constructing composite indicators: Methodology and user guide.

Pearson, K. (1901). On lines and planes of closest fit to systems of points in space. Philosophical Magazine., 2(11), 559-572.

Qiu, X. Y., Srinivasan, P., \& Hu, Y. (2014). Supervised learning models to predict firm performance with annual reports: An empirical study. Journal of the American Society for Information Science and Technology, 65(2), 400-413. https://doi.org/10.1002/asi.22983

Ribeiro, B., \& Lopes, N. (2011). Deep belief networks for financial prediction. In B. L. Lu, L. Zhang \& J. Kwok (Eds.), Lecture Notes in Computer Science: Vol. 7064. Neural information processing. ICONIP 2011 (pp 766-773). Springer. https://doi.org/10.1007/978-3-642-24965-5_86

Saporta, G., \& Stefanescu, M. V. (1996). Analiza datelor şi informatică. Economica Press.

Shen, F., Chao, J., \& Zhao, J. (2015). Forecasting exchange rate using deep belief networks and conjugate gradient method. Neurocomputing, 167, 243-253. https://doi.org/10.1016/j.neucom.2015.04.071

Situm, M. (2013). Business failure prediction models based on expert knowledge. Czech Journal of Social Sciences, Business, and Economics, 2(4), 28-45. http://www.cjssbe.cz/journal-archive/

Smith, M. J., \& Taffler, R. J. (2000). The chairman's statement - A content analysis of discretionary narrative disclosures. Accounting, Auditing, and Accountability Journal, 13(5), 624-646. https://doi.org/10.1108/09513570010353738

Song, Y. G., Cao, Q. L., \& Zhang, C. (2018). Towards a new approach to predict business performance using machine learning. Cognitive Systems Research, 52, 1004-1012. https://doi.org/10.1016/j.cogsys.2018.09.006

Sutskever, I., Vinyals, O., \& Le, Q. V. (2014, December). Sequence to sequence learning with neural networks. In Proceedings of the $27^{\text {th }}$ International Conference on Neural Information Processing Systems (Vol. 2, pp. 3104-3112).

Taylor, G., Tower, G., \& Neilson, J. (2014). Corporate communication of financial risk. Accounting \& Finance, 50(2), 417-446. https://doi.org/10.1111/j.1467-629X.2009.00326.x

Vochozka, M., \& Machova, V. (2018). Determination of value drivers for transport companies in the Czech Republic. Naše more, 65(4), 197-201. https://doi.org/10.17818/NM/2018/4SI.6

Vochozka, M., \& Sheng, P. (2016). The application of artificial neural networks on the prediction of the future financial development of transport companies. Communications, 2, 62-67.

West, D., Dellana, S., \& Qian, J. (2005). Neural network ensemble strategies for financial decision applications. Computers \& Operations Research, 32(10), 2543-2559. https://doi.org/10.1016/j.cor.2004.03.017

Zhang, W., Cao, Q., \& Schniederjans, M. (2004). Neural network earnings per share forecasting models: A comparative analysis of alternative methods. Decision Sciences, 35(2), 205-237. https://doi.org/10.1111/j.00117315.2004.02674.x 